Michael Joannidis

Lui G. Forni

\section{Severe viral infection and the kidney: lessons learned from the H1N1 pandemic}

Received: 23 December 2010

Accepted: 9 January 2011

Published online: 11 March 2011

(C) Copyright jointly held by Springer and ESICM 2011

This editorial refers to the articles available at: doi: 10.1007/s00134-011-2166-8 and doi:10.1007/s00134-011-2167-7; related correspondence can be found at: doi:10.1007/s00134-011-2183-7.

\section{Joannidis (}

Medical Intensive Care Unit, Department of Internal Medicine I, Medical University Innsbruck,

Anichstrasse 35, 6020 Innsbruck, Austria

e-mail: michael.joannidis@i-med.ac.at

L. G. Forni

Department of Critical Care,

Western Sussex Hospitals Trust Honorary Senior Lecturer,

Brighton \& Sussex Medical Schools, Brighton, UK

Through the development and application of the risk of renal failure, injury to the kidney, failure of kidney function, loss of kidney function, and end-stage kidney disease (RIFLE)/Acute Kidney Injury Network (AKIN) criteria for acute kidney injury, uncertainties about definitions have finally ended [1]. However, the term acute kidney injury (AKI) shares some similarities with that of acute respiratory distress syndrome (ARDS) given that these 'definitions' provide no information as to the underlying specific aetiologies. Clearly the cause of AKI determines treatment but also has been shown to influence both prognosis and outcome [2]; for example, sepsisrelated AKI is associated with particularly high mortality rates approaching 70\% in some studies [3] and is usually attributed to bacterial infections, less so to fungal causes and rarely to a viral aetiology [4].
The Cinderella view of viral disease in the intensive care unit (ICU) has changed dramatically over the last decade with the initial appearance of severe acute respiratory syndrome (SARS) and more recently that of the pandemic influenza A (H1N1) infections during 2009, which have presented new challenges to intensivists. Two clinical studies in this current issue of Intensive Care Medicine specifically address AKI in the setting of severe influenza infection. Pettilä and coworkers [5] from Australia and New Zealand present data from 628 critically ill patients which report an incidence of AKI in patients with H1N1 infection of approximately 34\%. Eighteen percent of these reached RIFLE class failure, and approximately $5 \%$ required renal replacement therapy (RRT). In keeping with other studies, mortality was highest in the RIFLE failure group (ca. 40\%) [6]; interestingly, however, mortality did not appear to be related to the need for RRT. Multivariate analysis revealed the usual suspects of increased age, any Acute Physiology and Chronic Health Evaluation (APACHE) III co-morbidity and mechanical ventilation as independent risk factors for hospital mortality as well as AKI of whatever stage. In addition, the authors found that elevated creatine kinase (CK) levels correlated with RIFLE stages in a subgroup of 120 patients (where CK levels were available), indicating that pigment nephropathy may play a significant role in the pathogenesis of H1N1-associated AKI.

The second study focusses on a more severe subgroup of patients, with Nin and coworkers [7] presenting data from 84 critically ill patients from 13 ICUs across Spain and South America. Only patients with viral pneumonia were included, and an incidence of AKI of around 50\% was demonstrated, associated with higher mortality rates (40-78\%). However, 30 patients were excluded from analysis through lack of data, which may have influenced the results significantly. In this study, $24 \%$ of patients required RRT and had an observed mortality of $74 \%$, which is in keeping with data reported from studies in 
sepsis-associated AKI [3]. The majority of patients acquired AKI within $48 \mathrm{~h}$ of ICU admission. This cohort showed significantly better prognosis with higher reversibility and less requirement of RRT compared with those developing AKI later. Multivariate analysis revealed that late AKI (i.e. $>48 \mathrm{~h}$ ) but not RRT itself was associated with increased ICU mortality. The authors conclude that haemodynamic instability may be responsible for the AKI observed early and this is frequently 'reversible' after volume replacement. Late AKI represents rather persistent injury and is most likely influenced by co-morbidities or indeed a differing pathological process. Additionally, a letter by Nin and coworkers [8] describes the histological features from four deceased patients with H1N1 infection. Two patients with AKI showed the classical picture of acute tubular necrosis in the distal tubules, although the presence of viral nucleoprotein could also be demonstrated. In addition to tubular cells, periodic acid-Schiff (PAS)-positive intracytoplasmic granules could also be found in the parietal and visceral epithelia of the Bowman's capsule despite antiviral treatment. Endothelial lesions could not be detected.

The observation that critically ill patients with H1N1 also demonstrate a high prevalence of AKI is neither new nor unexpected [9-11]. The studies presented in this issue of ICM, however, do provide some answers to the question about the pathophysiology of viral-associated AKI. There is abundant data in the nephrological literature on viral disease presenting with significant renal manifestations; for example, chronic viral infections including hepatitis $\mathrm{B}$ and $\mathrm{C}$ or human immune-deficiency virus (HIV) usually manifest with glomerular disease with classical features including membranoproliferative glomerulonephritis (GN), membranous nephropathy or (collapsing) focal segmental glomerulurosclerosis. The pathological mechanisms behind these manifestations are either immune complex deposition or immune reactions resulting in glomerular membrane proliferation. Rarely do viral diseases result in the more severe form of rapidly progressive GN presenting as AKI. Rapid deterioration of renal function is seen with hantavirus-type infection (e.g. Hantaan, Dobrava, Puumala, Sin Nombre), often resulting in requirement of RRT $[12,13]$. Fulminant organ failure has been described in these and other viral diseases, especially due to Balkan and Asian strains manifesting as haemorrhagic fever with renal syndrome (HFRS) [12, 13]. Renal failure in this context appears to be based on severe coagulopathy, endothelial damage and increased vascular permeability, with some similarities to sepsis with disseminated intravascular coagulation resulting directly in impaired organ perfusion and subsequent tissue damage. Cytokine and humoral factor mediated acute interstitial nephritis may play a contributing role. Another frequent complication reported in many viral infections, including HIV, Coxsackie, Epstein-Barr, herpes simplex, adeno-, echo- and cytomegalovirus as well as parainfluenza and influenza $A$ and $B$ virus is that of severe myositis resulting in massive release of myoglobin and, as a consequence, pigment-associated AKI [11, 14, 15]. Perhaps the most recently, and comprehensively, studied viral infection in the critically ill prior to the H1N1 pandemic is that of the novel coronavirus (SARS-CoV) associated with the severe acute respiratory syndrome reported in Hong Kong and surrounding regions. Unsurprisingly, several similarities between $\mathrm{H} 1 \mathrm{~N} 1$ and SARS-CoV are demonstrated. In one large study on patients with SARS, renal involvement occurred in only $6.7 \%$, but this included all hospitalized patients, whereas in those with SARS who developed renal failure the mortality was over $90 \%$ [16]. In keeping with the studies on H1N1 there appeared to be a significant pre-renal element, although again acute tubular necrosis with a predominantly distal tubule distribution was described, as was rhabdomyolysis associated with myositis [17]. The nature of the renal lesion was thought to be through an exuberant host response rather than through uncontrolled viral infection in the kidney. Furthermore, crude markers of tubular function including increased fractional excretion of uric acid coupled with hypouricaemia were observed in patients who subsequently developed AKI [18].

So what causes acute kidney injury in severe H1N1 infection? Analysis of the three studies described allows some conclusions to be drawn. Firstly, the high rate of 'early AKI' with less requirement for RRT and higher rates of recovery indicates an early haemodynamic component due to hypovolaemia or vasodilatory shock due to an exaggerated host response [7]. Secondly, the association between CK and RIFLE stage indicates rhabdomyolysis as an additional mechanism in those patients suffering from myositis [5]. However, the incidence and outcome of AKI do seem to be significantly influenced by co-morbidities and the requirement of mechanical ventilation. Furthermore, the role of supraadded infection, particularly in those patients with a longer ICU course, cannot be ignored and may have been significant in those developing 'late' AKI. Finally the histological investigation shows the classical picture of acute tubular necrosis (with predominantly distal tubular involvement) and viral particles in epithelial cells as well as the Bowman's capsule. Clearly these findings differ significantly from those reported in patients dying from (bacterial) septic shock [19], where increased rates of apoptosis in renal tubular epithelia as well as leucocytic infiltration in glomeruli and capillaries are found. Hence, the role of direct viral infiltration in the pathogenesis of H1N1-associated AKI still remains to be further established.

In terms of prevention of AKI, these studies tell us that measures similar to early goal-directed therapy in sepsis to avoid prolonged hypoperfusion are of utmost importance [20]. Forced isovolaemic diuresis may be considered in cases of severe myositis to prevent haem 
pigment nephropathy. Risk factors for development of AKI should be avoided if at all possible (e.g. nephrotoxins). The role of antiviral therapy such as neuraminidase inhibitors in terms of protection against AKI remains unclear from these studies. Nin and coworkers showed that the ICU mortality in patients treated with neuraminidase inhibitors remained high at
$53 \%$ (of 77 patients), slightly lower than the $71 \%$ mortality in those who were not treated, but this cohort included only 7 patients [7]. However, it may be that neuraminidase treatment occurred too late in the course of disease to influence outcome.

Conflict of interest The authors declare no conflict of interest.

\section{References}

1. Molitoris BA, Levin A, Warnock DG, Joannidis M, Mehta RL, Kellum JA, Ronco C, Shah S (2007) Improving outcomes from acute kidney injury. J Am Soc Nephrol 18:1992-1994

2. Joannidis M, Metnitz PG (2005) Epidemiology and natural history of acute renal failure in the ICU. Crit Care Clin 21:239-249

3. Bagshaw SM, Uchino S, Bellomo R, Morimatsu H, Morgera S, Schetz M, Tan I, Bouman C, Macedo E, Gibney N, Tolwani A, Oudemans-van Straaten HM, Ronco C, Kellum JA (2007) Septic acute kidney injury in critically ill patients: clinical characteristics and outcomes. Clin J Am Soc Nephrol 2:431-439

4. Martin GS, Mannino DM, Eaton S, Moss M (2003) The epidemiology of sepsis in the United States from 1979 through 2000. N Engl J Med 348:1546-1554

5. Pettilä V, Webb SA, Bailey M, Howe B, Seppelt IM, Bellomo R (2011) Acute kidney injury in patients with influenza A (H1N1) 2009. Intensive Care Med. doi:10.1007/s00134-011-2166-8

6. Joannidis M, Metnitz B, Bauer P, Schusterschitz N, Moreno R, Druml W, Metnitz PG (2009) Acute kidney injury in critically ill patients classified by AKIN versus RIFLE using the SAPS 3 database. Intensive Care Med 35:1692-1702

7. Nin N, Ríos F, Lorente JA, Soto L, Hurtado J, Arancibia F, Apezteguia C, Ugarte S, Echevarría E, Cortez I, Bujedo G, Frutos F, Esteban A (2011) Acute renal failure in critically ill patients with influenza A (H1N1) viral pneumonia: an observational study. Intensive Care Med. doi: 10.1007/s00134-011-2167-7
8. Nin N, Lorenta JA, Sánchez-Rodríguez C, Granados R, Ver LS, Soto L, Hidalgo J, Ortin J, Fernández-Segoviano P, Esteban A (2011) Kidney histopathological findings in fatal pandemic 2009 influenza A (H1N1). Intensive Care Med. doi: 10.1007/s00134-011-2183-7

9. Rello J, Rodriguez A, Ibanez P, Socias L, Cebrian J, Marques A, Guerrero J, Ruiz-Santana S, Marquez E, Del NogalSaez F, varez-Lerma F, Martinez S, Ferrer M, Avellanas M, Granada R, Maravi-Poma E, Albert P, Sierra R, Vidaur L, Ortiz P, Prieto dP I, Galvan B, Leon-Gil C (2009) Intensive care adult patients with severe respiratory failure caused by Influenza A (H1N1)v in Spain. Crit Care 13:R148

10. Sood MM, Rigatto C, Zarychanski R, Komenda P, Sood AR, Bueti J, Reslerova M, Roberts D, Mojica J, Kumar A (2010) Acute kidney injury in critically ill patients infected with 2009 pandemic influenza $\mathrm{A}(\mathrm{H} 1 \mathrm{~N} 1)$ : report from a Canadian Province. Am J Kidney Dis 55:848-855

11. Shenouda A, Hatch FE (1976) Influenza A viral infection associated with acute renal failure. Am J Med 61:697-702

12. Markotic A, Nichol ST, Kuzman I, Sanchez AJ, Ksiazek TG, Gagro A, Rabatic S, Zgorelec R, vsic-Zupanc T, Beus I, Dekaris D (2002)

Characteristics of Puumala and Dobrava infections in Croatia. J Med Virol 66:542-551

13. Muranyi W, Bahr U, Zeier M, van der Woude FJ (2005) Hantavirus infection. J Am Soc Nephrol 16:3669-3679

14. Abe M, Higuchi T, Okada K, Kaizu K, Matsumoto K (2006) Clinical study of influenza-associated rhabdomyolysis with acute renal failure. Clin Nephrol 66:166-170
15. D'Silva D, Hewagama S, Doherty R, Korman TM, Buttery J (2009) Melting muscles: novel H1N1 influenza A associated rhabdomyolysis. Pediatr Infect Dis J 28:1138-1139

16. Chu KH, Tsang WK, Tang CS, Lam MF, Lai FM, To KF, Fung KS, Tang HL, Yan WW, Chan HW, Lai TS, Tong KL, Lai KN (2005) Acute renal impairment in coronavirus-associated severe acute respiratory syndrome. Kidney Int 67:698-705

17. Wu VC, Hsueh PR, Lin WC, Huang JW, Tsai HB, Chen YM, Wu KD (2004) Acute renal failure in SARS patients: more than rhabdomyolysis. Nephrol Dial Transplant 19:3180-3182

18. Wu VC, Huang JW, Hsueh PR, Yang YF, Tsai HB, Kan WC, Chang HW, Wu KD (2005) Renal hypouricemia is an ominous sign in patients with severe acute respiratory syndrome. Am J Kidney Dis 45:88-95

19. Lerolle N, Nochy D, Guerot E, Bruneval P, Fagon JY, Diehl JL, Hill G (2010) Histopathology of septic shock induced acute kidney injury: apoptosis and leukocytic infiltration. Intensive Care Med 36:471-478

20. Joannidis M, Druml W, Forni LG, Groeneveld AB, Honore P, Oudemansvan Straaten HM, Ronco C, Schetz MR, Woittiez AJ (2010) Prevention of acute kidney injury and protection of renal function in the intensive care unit. Expert opinion of the Working Group for Nephrology, ESICM. Intensive Care Med 36:392-411 